\title{
Sonological Evaluation of Major Salivary Gland Lesions with Histopathological Correlation
}

\author{
Anto J Richie ${ }^{1}$, Mellonie $\mathbf{P}^{2}$ \\ ${ }^{1}$ Associate Professor, Department of Radiology, ${ }^{2}$ Assistant Professor, Department of Pathology, Father Muller Medical \\ College and Hospital, India
}

Corresponding author: Mellonie. P, 501, Muller Nest, Jeppu Main Road, Kankanady, Mangalore- 575002, India

DOI: http://dx.doi.org/10.21276/ijcmsr.2019.4.2.21

How to cite this article: Anto J Richie, Mellonie P. Sonological evaluation of major salivary gland lesions with histopathological correlation. International Journal of Contemporary Medicine Surgery and Radiology. 2019;4(2):B91-B94.

\section{A B S T R A C T}

Introduction: Major salivary glands display complex pathology comprising of various lesions ranging from neoplastic to inflammatory to degenerative cystic lesions. Ultrasonography plays pivotal role in choosing the appropriate treatment plan. However final diagnosis has to be confirmed by histopathology. Aim of this study was to establish the existing correlation between preoperative ultra-sonogram and postoperative histopathological examination, in patients with surgically resected major salivary gland lesions.

Material and methods: This retrospective study was conducted in Father Muller Medical College and Hospital. All patients with major salivary gland lesions who have undergone preoperative ultra-sonogram and post-operative histopathological evaluation between January 2017 to December 2018 for a period of 2 years were included in the study. Different characteristics such as size, shape, homogeneity, vascularization and delimitation were assessed on ultrasonography and then compared with histopathological findings.

Results: Our study included 57 patients out of which majority of lesions were of parotid gland. There was increased incidence in $5^{\text {th }}$ decade, also a male preponderance was observed. Correlation was better for benign lesions and $100 \%$ correlation was observed for pleomorphic adenoma. Overall diagnostic accuracy for ultrasonography was $85.7 \%$. There was $100 \%$ correlation for homogeneity, vascularization and delimitation. There was correlation for size and shape for both benign and malignant lesions.

Conclusion: This study emphasises the importance of ultrasound in diagnosing major salivary gland lesions. Although the sensitivity of ultrasound is not as expected, ultrasound is still a promising diagnostic tool that may be used in first line diagnosis of major salivary gland lesions.

Keywords: Ultrasonography, Major Salivary Gland Lesions, Histopathology, Pleomorphic Adenoma.

\section{INTRODUCTION}

Worldwide annual incidence of salivary gland tumours varies from 0.5 to $13.5 \%$ per 1 lakh population. ${ }^{1}$ Overall about $3-5 \%$ of head and neck cancers are salivary gland neoplasms. ${ }^{2}$ Pleomorphic adenoma is the most commonly encountered benign tumour of the major salivary gland. ${ }^{3}$ However pathology of major salivary gland is quite complex. Ultrasound is one of the preliminary investigations of choice that helps clinical diagnosis. ${ }^{4}$ Ultrasonography is a simple easily assessable, non-invasive, low-cost imaging technique that can be repeated, if necessary. ${ }^{5}$ The only disadvantage of ultrasonography is its subjective interpretation depending on the radiologist's expertise. Fine needle aspiration biopsy (FNAB) or post-operative histopathological evaluation is more definitive to determine nature of lesion, whether benign or malignant. ${ }^{7}$ There is a need to assess the existing correlation between ultrasonography and histopathological evaluation in major salivary gland lesions.

Aim: Aim of this study is to establish the existing correlation between preoperative ultra-sonogram and postoperative histopathological examination, in patients who have been operated for major salivary gland lesions.

\section{MATERIAL AND METHODS}

This retrospective study was conducted in Father Muller Medical College and Hospital. All patients with major salivary gland lesions who have undergone preoperative ultra-sonogram and post-operative histopathological evaluation between January 2017 to December 2018 for a period of 2 years were included in the study. In all cases ultrasound was done using a high-frequency transducer (7.5-12 MHz). Ultrasonography was performed less than two months prior to surgery. Different characteristics such as size, shape, homogeneity, vascularization and delimitation were assessed on ultrasonography. In addition, echo-doppler was done to depict the peripheral and central vascularization, also the lesion's relation to the intraglandular vessels; finally, an ultrasonography diagnosis was made. Histopathological evaluation was done on haematoxylin and eosin stained 
slides. The specimens obtained by surgery were fixed for 6 to 48 hours in $10 \%$ buffered formalin and then embedded in paraffin blocks. Four- $\mu \mathrm{m}$ thin sections were obtained from these paraffin blocks and stained with Haematoxylin and Eosin stain. In certain cases immunohistochemical (IHC) staining was done on semi automated biogenics IHC machine using readily usable biogenics antibodies. IHC reports were retrieved from register. The data collected were entered in excel sheet. Regarding dimensions, lesions were evaluated in two dimensions by ultrasonography, and in three dimensions in histopathology report. Results were considered similar when two of the three macroscopic dimensions mentioned in the histopathology report, were close to the US dimensions. Variation of $3 \mathrm{~mm}$ was acceptable.

\section{STATISTICAL ANALYSIS}

Statistical analysis was performed using SPSS software. Categorical variables were summarized as percentages and sensitivity, specificity and diagnostic accuracy of ultrasonography was evaluated.

\section{RESULTS}

Our study included 57 patients out of which majority of lesions were of parotid gland. There was increased incidence in $5^{\text {th }}$ decade, also a male preponderance was observed. Ultrasound diagnosis correlated with $86.5 \%$ of histopathology results. Correlation of ultrasonography parameters and histopathology findings was better for malignant tumours (Table-1).

On Histopathological evaluation the most common benign tumour encountered in major salivary gland was pleomorphic

\begin{tabular}{|c|c|c|c|}
\hline \multirow[t]{2}{*}{ Age group } & \multicolumn{2}{|c|}{ Gender } & \multirow{2}{*}{$\begin{array}{l}\text { No of cases } \\
\text { (percentage) }\end{array}$} \\
\hline & Male & Female & \\
\hline$<20$ & 3 & 2 & $5(8.7 \%)$ \\
\hline $21-30$ & 6 & 3 & $9(15.4 \%)$ \\
\hline $31-40$ & 6 & 5 & $11(19.2 \%)$ \\
\hline $41-50$ & 9 & 4 & $13(22.8 \%)$ \\
\hline $51-60$ & 4 & 3 & $7(12.2 \%)$ \\
\hline $61-70$ & 5 & 3 & $8(14 \%)$ \\
\hline$>70$ & 2 & 2 & $4(7 \%)$ \\
\hline Total no of cases & $35(61.4 \%)$ & $22(38.5 \%)$ & 57 \\
\hline \multicolumn{4}{|c|}{ Table-1: } \\
\hline
\end{tabular}

\begin{tabular}{|l|c|c|}
\hline His pathological diagnosis & No of cases & \% of cases \\
\hline Chronic sialadenitis & 12 & $21 \%$ \\
\hline Retention cyst & 3 & $5.2 \%$ \\
\hline Lymphoepithelial cyst & 4 & $7 \%$ \\
\hline Dermoid cyst & 2 & $3.5 \%$ \\
\hline Complex vascular lesion & 1 & $1.7 \%$ \\
\hline Pleomorphic adenoma & 16 & $28 \%$ \\
\hline Warthins tumour & 9 & $15.7 \%$ \\
\hline Mucoepidermoid carcinoma & 4 & $7 \%$ \\
\hline Adenoid cystic carcinoma & 2 & $3.5 \%$ \\
\hline Acinic cell carcinoma & 2 & $2.5 \%$ \\
\hline Myoepithelial carcinoma & 1 & $1.7 \%$ \\
\hline \multicolumn{2}{|||}{ Table-2: } \\
\hline
\end{tabular}

adenoma. The distribution of cases on histopathology evaluation is depicted in table 2

Pleomorphic adenoma was the most commonly encountered lesion in major salivary gland (16 cases, 28\%). Of these 12 were from parotid gland and 4 were of submandibular gland. The parotid pleomorphic adenoma had 100\% correspondence of different characters like shape, consistency, vascularization, homogeneity and delimitation. However dimensions correlated in only $45.7 \%$ of cases. Remaining cases showed smaller dimension on ultrasound. Also of the 16 cases 1 case was wrongly diagnosed as lymphadenopathy in ultrasonography.

For submandibular pleomorphic adenomas (4 cases, 7\%) the diagnosis and all compared characteristics correlated in

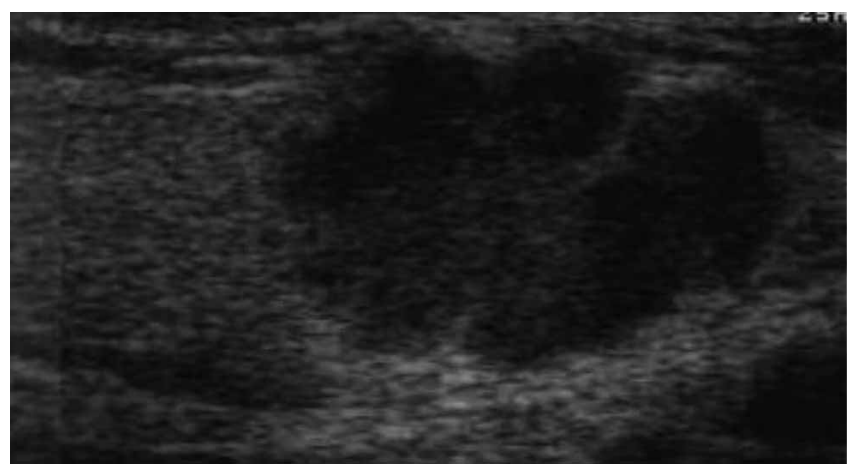

Figure-1: Ultrasound image of Warthin's tumour

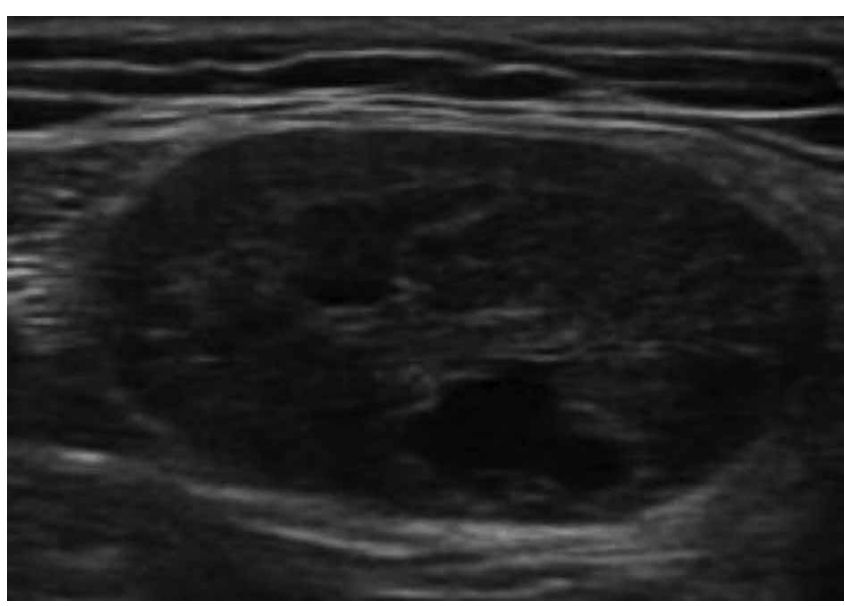

Figure-2: Ultrasound image of Warthin's tumour

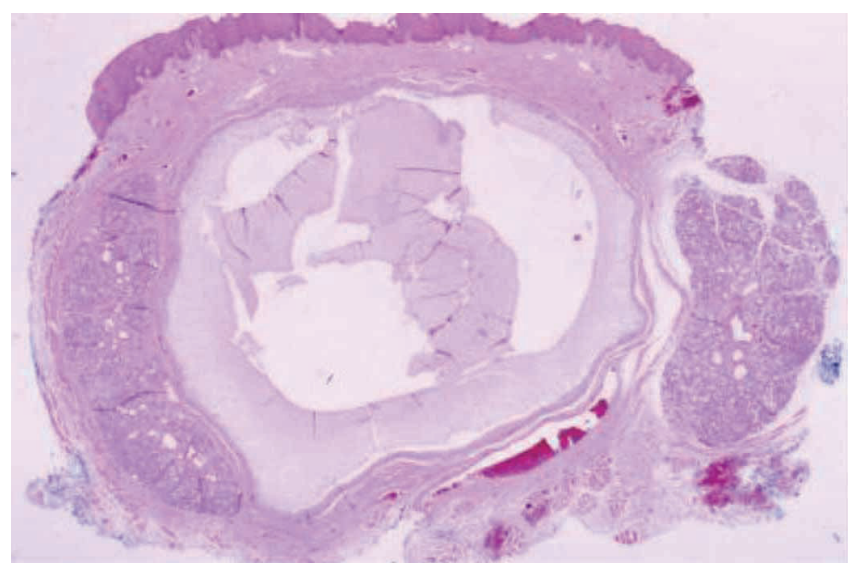

Figure-3: Histopathology image of Mucous rentention cyst 
$100 \%$ of cases. Following pleomorphic adenoma the next benign tumour of major salivary gland encountered in this study was Warthins tumour. All the 9 cases of Warthins tumour were of parotid gland. Concordance for shape, homogeneity and delimitation was $100 \%$ for these cases. Size concordance was seen only in $65 \%$ of cases. Other cases had smaller dimension on ultrasonography (Figure-1,2). Also there was one case diagnosed as lymphadenopathy in ultrasound which turned out to be Warthins tumour. Also one case of complex vascular lesion (1.7\%) found in parotid gland, showed 100\% correspondence for shape, vascularization and homogeneity but the size was found to be bigger on ultrasonography. There was $100 \%$ concordance for diagnosis. Regarding the malignant tumours of parotid gland there was $100 \%$ concordance for all characteristics including diagnosis. Regarding the 3 malignant tumour of submandibular salivary gland encountered, one case was not detected on ultrasound. In chronic parotid gland sialadenitis (12 cases 21\%), the study revealed, 100\% correlation between ultrasonography and histopathological evaluation for diagnosis. Also the concordance was $100 \%$ for shape, consistency, vascularization, homogeneity and delimitation. Only 75\% cases showed size concordance. Size was bigger in ultrasound compared to histopathological evaluation. Of the 9 cystic lesions (16.1\%), 6 were of parotid gland and 2 were of submandibular gland. For lymphoepithelial cyst and mucous retention cyst(figure 3) correspondence was $100 \%$ for shape, vascularization, delimitation, homogeneity and diagnosis. $65 \%$ concordance was observed for size. For dermoid cyst size was bigger on ultrasound and other parameters couldn't be assessed. Overall diagnostic accuracy for ultrasonography for benign lesions was $85.7 \%$.

Coming to malignant tumours of major salivary gland, this study had a higher incidence of malignant tumours (15.7\%), probably because it was conducted in an Oncology referral centre. Of the nine malignant tumours, 6 were of sublingual gland and it included 2 cases of Acinic cell carcinoma, 2 cases of Mucoepidermoid carcinoma. 1 case of Myoepithelial carcinoma and 1 case of adenoid cystic carcinoma. Apart from these 2 cases of Mucoepidermoid carcinoma was seen in submandibular gland and 1 case of adenoid cystic carcinoma was found in parotid gland.

\section{DISCUSSION}

Salivary gland tumours are not very common. More so over only $5-10 \%$ of all these tumours are malignant. It is beneficial for the patient if these tumours are diagnosed preoperatively. There are three pairs of major salivary glands, namely Parotid, Submandibular and Sublingual. The size of the salivary gland is inversely proportional to the tumour detected being malignant. ${ }^{9}$ Ultrasound is the first modality of choice in evaluating salivary gland neoplasms. However on sonographic evaluation many benign and malignant tumours have similar appearance. Some features like indistinct margins, heterogeneous echo texture, regional lymph node enlargement and absence of distal acoustic enhancement have been reported more frequently in malignant. ${ }^{10}$ Thus clinical examination and ultrasonography helps to narrow down the differential diagnosis. However histopathological evaluation still remains the gold standard.

In this study we have tried to establish the existing correlation between ultrasonography and histopathological diagnosis and also to find the concordance of features like size, shape, homogeneity, vascularization and delimitation observed in ultrasonography. Age of the patients varied from 18 to 79 years. A peak in incidence was observed in the $4^{\text {th }}$ decade. Kakoty et al and Issac et al reported similar findings. ${ }^{11,12}$ The most common benign tumour diagnosed in ultrasonography was pleomorphic adenoma. Many other studies in literature also are assertive about this. ${ }^{13,14}$ But study done by Vijay et al and Schick et al showed an equal incidence of pleomorphic adenoma and warthin's tumour. ${ }^{15,16}$ Ultrasonography features such as poor peripheral vascularization, sharp borders, lobulation and homogeneity are specific for pleomorphic adenoma. ${ }^{8}$ The same was observed in ours study. Warthin tumours have cystic central content (transonic), with central vascularization less abundant than in pleomorphic adenomas. ${ }^{10}$ Thus it is mostly unlikely to confuse between pleomorphic adenoma and Warthin tumour on ultrasonography. Ultrasonography of chronic sialadenitis showed $100 \%$ concordance in this study which is higher compared to the study done by Wu s et al. ${ }^{17}$ Ultrasonography features of chronic sialolithiasis observed in this study were heterogeneity, pseudonodular shape, increased vascularity, hyperechoeic with subcentemetric nodes, 5 cases also had sialoliths measuring 5 to $8 \mathrm{~mm}$. Histopathology confirmed the diagnosis in all the 12 cases. Features seen were acinar atrophy, increased periacinar fibrosis, association of chronic inflammatory infiltrate with variable squamous metaplasia of ductal lining epithelium. Cystic lesions had $100 \%$ concordance for shape, vascularization, delimitation, homogeneity and diagnosis. However size was bigger in ultrasonography, possibly because of evacuation of cyst contents intraoperatively. ${ }^{18}$ Histopathology revealed cysts were lined by mucinous lining in case of retention cyst, lymphoepithelial islands in case of lymphoepithelial cysts, and squamous epithelium in case of dermoid cyst. ${ }^{19}$ The diagnostic accuracy for malignant salivary gland tumours was $100 \%$ in our study which is higher when compared to the study done by Chandak et al. ${ }^{20}$

\section{CONCLUSION}

Ultrasonography is very useful in initial workup of the patients with major salivary gland lesions. However histopathological evaluation still remains the gold standard. Studies with bigger sample size should be conducted to further evaluate the pitfalls of ultrasonography in diagnosing cystic lesions of salivary glands.

\section{REFERENCES}

1. Scher RL, Oostingh PE, Levine PA, Cantrell RW, Feldman PS. Role of fine needle aspiration in the diagnosis of lesions of the oral cavity, oropharynx, and nasopharynx. Cancer 1988; 62(12): 2602-6.

2. Speight PM, Barrett AW. Salivary gland tumours. Oral Dis 2002; 8(5): 229-40.

3. Enescu AS, Mărgăritescu CL, Crăiţoiu MM, Enescu A, Crăiţoiu Ş. The involvement of growth differentiation 
factor 5 (GDF5) and aggrecan in the epithelialmesenchymal transition of salivary gland pleomorphic adenoma. Rom J Morphol Embryol, 2013;54(4):969976.

4. Lee YY, Wong KT, King AD, Ahuja AT. Imaging of salivary gland tumours. Eur J Radiol. 2008;66:419-436.

5. Welkoborsky HJ. Current aspects in ultrasonography of the salivary glands. HNO 2011;59(2):155-165.

6. Klein K, Türk R, Gritzmann N, Traxler M. The value of sonography in salivary gland tumors. HNO 1989; 37(2):71-75.

7. Tessy PJ, Jayalekshmy PS, Cicy PJ, Poothiode U. Fine needle aspiration cytology of salivary gland lesions with histopathological correlation:A two year study. Int J Healthc Biomed Res 2015; 3(4): 91-9.

8. Dumitriu D, Dudea S, Badea R, Botar-Jid C, Băciut G, Băciut M. B-mode and colour Doppler ultrasound features of salivary gland tumours. Med Ultrason 2008;10:31-37.

9. Gritzmann N, Hollerweger A, Macheiner P, Rettenbacher T, Hubner E. Sonography of the salivary glands. European Radiology 2003; 13:364-375.

10. Kovacevic DO, Fabijanic I. Sonographic diagnosis of parotid gland lesions: correlation with the results of sonographically guided fi ne-needle aspiration biopsy. J Clin Ultrasound 2010;38:294-8.

11. Kakoty S, Baruah TD, Babu CPG. FNAC and histopathological correlation of salivary gland lesions: An observational study. Int Surg J 2017;4(7): 2148-52.

12. Isaac U, Isaac JS, Isaac AD. Fine needle aspiration cytology of oral lesions. Pak Oral Dent J 2013; 33(2): 266-70.

13. Mazaher H, Kashany SS, Sharifi an H. Diagnostic accuracy of triplex ultrasound in malignant parotid tumours. Iran J Radiol 2007;4:169-174.

14. Bradley MJ, Durham LH, Lancer JM. The role of colour $\mathrm{fl}$ ow Doppler in the investigation of the salivary gland tumour. Clin Radiol 2000;55:759-762.

15. Vijai Pratap, S K Jain. "Sonographic Evaluation of Salivary Gland Tumors - A Hospital Based Study". International Journal of Scientifi c Study. 2014;1(4):3236.

16. Steiner E, Gahleitner A, Böhm P, Helbich T, BaSsalamah A, et al. Differentiation of benign and malignant tumours of the parotid gland: value of pulsed Doppler and colour Doppler sonography. Eur Radiol 1998;8(4):1462-1467.

17. Wu S, Liu G, Chen R, Guan Y. Role of ultrasound in the assessment of benignity and malignancy of parotid masses. Dentomaxillofac Radiol, 2012, 41(2):131-135.

18. Pallagatti S, Sheikh S, Puri N, Mittal A, Singh B. To evaluate the efficacy of ultrasonography compared to clinical diagnosis, radiography and histopathological findings in the diagnosis of maxillofacial swellings. Eur J Radiol, 2012, 81(8):1821-1827.

19. Carlson E, Ord R. Textbook and color atlas of salivary gland pathology: diagnosis and management. WileyBlackwell, Singapore, 2008, 3-216.

20. Chandak R, Degwekar S, Bhowte RR, Motwani M, Banode P, Chandak M, Rawlani S. An evaluation of efficacy of ultrasonography in the diagnosis of head and neck swellings. Dentomaxillofac Radiol 2011; 40(4):213-221.

\section{Source of Support: Nil; Conflict of Interest: None}

Submitted: 28-02-2019; Accepted: 17-05-2019; Published online: 09-06-2019 